\title{
Role of Diagnostic Office Hysteroscopy in Abnormal Uterine Bleeding and its Histopathological Correlation in Child Bearing Period
}

\author{
M.I. Mohamed, M.A.Abd El Fattah, S.N.Abo El Ezz and D.M.Mohamed \\ Obstetrics and Gynecology Dept., Faculty of Medicine, Benha Univ., Benha, Egypt \\ E-Mail:Dina26@gmail.com
}

\begin{abstract}
Strange uterine draining characterized as a seeping from uterine form which is irregular in volume, routineness or potentially timing that has been available for most of the most recent a half year. Assessment of the patients was by history taking, general and nearby assessment, research facility examinations, transvaginal ultrasonography, hysteroscopy and dilatation and curettage with biobsy. To evaluate the Role of Office Hysteroscopy in finding of Abnormal Uterine Bleeding and its Histopathological Correlation in Child Bearing Period. This examination was imminent observational investigation carried on 100 ladies of conceptive age bunch from 18-40 years took care of Benha college emergency clinics between November 2018 to November 2020 to assess the symptomatic and restorative function of office hysteroscopy in anomalous uterine draining and its histopathological connection in ladies inside kid bearing period. Office hysteroscopy had affectability of $88 \%$, explicitness of $84,2 \%$, positive prescient estimation of $96 \%$, negative prescient estimation of $61.5 \%$ and demonstrative precision of $87 \%$ for diagnosing the intrauterine reason for unusual uterine dying. Office hysteroscopy is a straightforward, essential and generally safe outpatient strategy which permits a satisfactory investigation of the uterine cavity under visual control.
\end{abstract}

Keywords: Abnormal Uterine Bleeding, Histopathology Examination, Hysteroscopy.

\section{Introduction}

Unusual uterine draining is a seeping from uterine create which is strange in volume, routineness and additionally timing that has been available for the vast majority of the most recent a half year. It could be unreasonably hefty or light and might be delayed, regular, or irregular [1] .

Albeit unusual uterine draining is a result which has numerous aetiological reasons, FIGO has grouped it into 9 principle classifications, which are masterminded by the abbreviation PALM-COEIN: Polyp; adenomyosis; leiomyoma; hyperplasia; danger; coagulopathy; ovulatory brokenness; endometrial causes (irritation, disease, variations from the norm in vasculogenesis and nearby hemostasis); iatrogenic and not yet arranged [2].

Different strategies to analyze the reason for AUB incorporate pelvic ultrasonography, sonohysterography, hysteroscopy and Dilatation and Curettage (D and C).

Dilatation and Curettage is a visually impaired technique and the endometrium must be shipped off the Pathologist to read histological examples and for the report. The co-activity of the Pathologist is significant. Ultrasonography unmistakably portrays the uterine form and the status of the ovary [3].

Office hysteroscopy is a fast, protected, all around endured, and profoundly exact methods for diagnosing the reason for unnecessary uterine dying. It grants patient and doctor to examine greater treatment choices before medical procedure, including outpatient employable hysteroscopic systems. This implies saving as expected and in medication, strategy, expert, and clinic costs [4].

\section{Methods}

This study was prospective observational study carried on 100 women of reproductive age group from 18-40 years complaining of abnormal uterine bleeding attended to Benha university hospitals in the period from November 2018 to November 2020.

The inclusion and exclusion criteria were applied and women who were eligible to share gave written consent to be rolled in the study after explaining the procedure to them .

All patients were undergoing office hysteroscopy followed by dilatation \& curettage with biopsy, specimens were sent for histopathological analysis.

\subsection{Inclusion criteria}

Patients with age between 18-40 years with AUB as shown by vaginal Examination and multiparous and nulliparous women.

\subsection{Exclusion criteria}

Pregnancy, Patients with profuse bleeding, Infection in the genital tract, Malignancies of the genital tract, Patient with intra uterine device, Patient with bleeding disorder and patient with iatrogenic cause.

Patients were subjected to a detailed history, local and general examination, investigations were done (hemoglobin $[\mathrm{Hb}] \%, \mathrm{ABO}$ ), bleeding time, clotting time and Transvaginal ultrasonography. Diagnostic office hysteroscopy was done for all patients in fully equipped room in Benha University Hospitals followed by dilatation and curettage with biobsy.

\subsection{Office Hysteroscopic examination}

Office hysteroscopy was done and reviewing the uterine hole: for attachments, polypi, submucous fibroids, endometrial hyperplasia, an appearance 
reminiscent of harm and some other pathology. The pathology was recorded and portrayed agreeing the shape, the size (which was assessed by contrasting the mass with uterine pit) and the site. hysteroscopic polypectomy was accomplished for certain cases with endometrial polyp.

Dilatation of cervix under broad sedation and curettage of the entire uterine depression was done, the biopsy was saved in $10 \%$ formaline and sent for histopathological assessment. The information from office hysteroscopy and dilatation \&curettage reports was looked at.

\subsection{Hysteroscopy Findings}

- Proliferative phase: endometrium is smooth and pink-white in color, gland opening $\mathrm{s}$ appear as white ringed elevation surrounded with netlike vessel.

- Secretory phase: Endometrium is lush and velvety.

- Hyperplasia: Thick hyper-vascular friable mucosa, and polypoid in appearance, further classified as simple or atypical by the pathologists

- Polyp: Soft intracavitary formation, which was easily mobilized and covered by mucosa with endometrial gland and no distended vascular network.

- Fibroid: Firm intracavitary formation with thin endometrial lining and superficial large blood vessels.

\section{Results}

This study was done in the Department of Obstetrics and Gynecology, Benha University Hospitals on 100 patients complaining of abnormal uterine bleeding at child bearing period to evaluate the role of office hysteroscopy in diagnosis of abnormal uterine bleeding..

In this study, the age of patients ranging from 1840 years and mean age of the study population was 37 years. Mean age of menarche was 12 years. Median gravidity and parity were 3 for each.55 patients $(55.0 \%)$ of the study population had previous cesarean section. As regard contraception, the most frequent method used was IUD $(30 \%)$ while the least frequent method used was COC \& POP (only 5\%).

In this study, the most frequent pattern of abnormal bleeding in the study population was menorrhagia $(65 \%)$ followed by metrorrhagia $(20.0 \%)$ then $(10 \%)$ intermenstrual and the least frequent pattern was menometrorrhagia $(5.0 \%)$.

The most frequent Office hysteroscopy finding was intrauterine polyp in 48 patients (48\%) followed by submucous fibroid in 18 patients $(18 \%)$ then endometrial hyperplasia in 6 patients $(6 \%)$, and atrophic endometrium in 5 patients $(5 \%) .20$ of the patients $(20 \%)$ showed normal office hysteroscopy findings and 3 patients $(3 \%)$ with intrauterine synechiae Table (1)

Table (1) Office hysteroscopy findings in the study population.

\begin{tabular}{lc}
\hline Office hysteroscopy findings & $\mathbf{n}(\%)$ \\
\hline Intrauterine polyp & $48(48.0)$ \\
SM Fibroid & $18(18.0)$ \\
Endometrial hyperplasia & $6(6.0)$ \\
Atrophic endometrium & $5(5.0)$ \\
Intrauterine synechiae & $3(3.0)$ \\
Normal & $20(20.0)$ \\
\hline
\end{tabular}

While comparing office hysteroscopy findings with histopathology, from 48 patients with polyp diagnosed by Office hysteroscopy,38 patients diagnosed by histopathology. From 18 patients with fibroid diagnosed by Office hysteroscopy, 10 patients diagnosed by histopathology. From 12 with endometrial hyperplasia diagnosed by histopathology,6 patients diagnosed by Office hysteroscopy. From 9 patients with atrophic endometrium diagnosed by histopathology, Office hysteroscopy succeeded to diagnose 5 patients. Only Office hysteroscope succeeded to diagnose intrauterine synechiae Table (2).

Table (2) Difference between D\&C findings \& Office hysteroscopy.

\begin{tabular}{cccc}
\hline & & \multicolumn{2}{c}{ Office hysteroscopy } \\
\hline & Polyp & 38 & 48 \\
& Fibroid & 10 & 18 \\
D\&C findings & Endometrial hyperplasia & 12 & 6 \\
& Atrophic endometrium & 9 & 5 \\
& Intrauterine synechiae & 0 & 3 \\
& NAD & 31 & 20 \\
& Total & 100 & 100 \\
\hline
\end{tabular}

Office hysteroscopy was $93 \%$ sensitive and $89.2 \%$ specific for endometrial polyp with accuracy 
of $94 \%$. It's $80 \%$ sensitive and $100 \%$ specific for submucosal with accuracy $96 \%$.

The sensitivity, specificity, positive predictive value, negative predictive value and accuracy for endometrial hyperplasia were 58\%, 70\%, 78\%, 69.3\% and $75 \%$ respectively.

The sensitivity, specificity, positive predictive value, negative predictive value and accuracy for intrauterine synechiae are $88 \%, 100 \%, 100 \%, 89.3 \%$ and $94 \%$ respectively Table (3)

Table (3) Diagnostic indices of office hysteroscopy in dedication of intrauterine lesions.

\begin{tabular}{lccccc}
\hline & Sensitivity & Specificity & PPV & NPV & Diagnostic accuracy \\
\hline Intrauterine polyp & $93 \%$ & $89.2 \%$ & $96 \%$ & $61.5 \%$ & $94 \%$ \\
SM Fibroid & $80 \%$ & $100 \%$ & $100 \%$ & $95.2 \%$ & $96 \%$ \\
Intrauterine synechiae & $88 \%$ & $100 \%$ & $100 \%$ & $89.3 \%$ & $94 \%$ \\
endometrial hyperplasia & $58 \%$ & $70 \%$ & $78 \%$ & $69.3 \%$ & $75 \%$ \\
\hline
\end{tabular}

No significant difference between two modalities was observed with respect to normal endometrium ( $p$ $=0.185)$. Histopathology diagnosed hyperplasia in significantly higher proportion of patients as compared to Office hysteroscopy $(\mathrm{p}=0.042)$. Office Hysteroscopy diagnosed significantly higher proportion of patients with submucous myoma $(\mathrm{p}=$ 0.012), and intrauterine polyp ( $\mathrm{p}=0.0468)$. Statistically, no significant difference between two modalities was observed with respect to other pathologies ( $\mathrm{p}<0.05$ ). Between Office hysteroscopy and hitopathology, an agreement for diagnosis was observed at 79/100 cases (79\%). Office hysteroscopy provided additional information in 8 cases of submucous myoma, 10 cases of intrauterine polyps, 3 cases of intrauterine adhesions (synechiae). Additionally, 6 cases diagnosed as hyperplasia by histopathology were also shown to have polyps by hysteroscopy.4 cases with atrophic endometrium diagnosed by histopathology. On the other hand, histopathology missed 3 cases of intrauterine Synechiae Table (4).

Table (4) Comparison of Office hysteroscopic and histopathological abnormalities.

\begin{tabular}{lcccc}
\hline $\mathbf{N}$ & Finding & Hysteroscopy & Histopatholgy & Significance \\
\hline & Normal & 20 & 31 & $\mathrm{P}=0.185$ \\
$\mathbf{1}$ & Atrophic & 5 & 9 & $\mathrm{P}=0.589$ \\
$\mathbf{2}$ & Endometrial hyperplasia & 6 & 12 & $\mathrm{P}=0.042^{*}$ \\
$\mathbf{3}$ & Polyp & 48 & 38 & $\mathrm{P}=0.0468^{*}$ \\
$\mathbf{4}$ & Submucous myoma & 18 & 10 & $\mathrm{P}=0.012^{*}$ \\
$\mathbf{5}$ & Synechiae & 3 & 0 & $\mathrm{P}=0.079$ \\
\hline
\end{tabular}

\section{Discussion}

Irregular uterine draining is one of the most wellknown grumblings with which a patient presents to a Gynecologist. Each lady will sooner or later in the course of her life have scenes of irregular dying [5].

Utilization of office hysteroscopy in unusual uterine draining is nearly supplanting blind curettage, as it "sees" and "chooses" the reason. This is on the grounds that the uterine hole can be noticed and the region with a pathology can be curetted. Truly, it is an eye in the uterus [6],[7].

Of each of the 100 patients in our investigation ,the commonest pathology was seen with Office hysteroscopy is intrauterine polyp in 48 patients (48\%) generally found in patients between 28-35 years, at that point submucous myoma 18 patients (18\%) found in patients from 35 to 40 years, the normal size of myoma was $2-6 \mathrm{~cm}$, at that point endometrial hyperplasia in 6 patients $(6 \%)$ ultimately atrophic endometrium (5\%).intrauterine synechia was seen in $3 \%$ of patients. Hysteroscopy precisely distinguished endometrial polyp, submucous fibroid, however not all instances of endometrial hyperplasia and atrophic endometrium. These discoveries are being upheld by an examination led by European culture of human generation and embryology (ESHREE)concludes that hysteroscopy with endometrial biopsy is the "Best quality level" examination for AUB [10].

In our examination histopathology demonstrated strange discoveries in $69 \%$ of patients ,38 patients with intrauterine polyps, 10 patients with SM fibroid ,9 patients with atrophic endometrium and 12 patients with endometrial hyperplasia .These discoveries composed with Hatem series(is a forthcoming observational investigation directed on 114 patients expects to survey the precision of hysteroscopy in assessment of unusual uterine draining and to connect hysteroscopic discoveries with histopathologic discoveries), histopathology indicated irregular discoveries in 76 cases $(66.6 \%)$. Of these, 33 cases (28.8\%) had hyperplasia, 24 cases (19.8\%) had polyps and 7 case had submucous myoma and Aisha and Shukar-ud-Din arrangement in which histopathology distinguished irregularities in $60 \%$ instances of which hyperplasia was available in $20 \%$ 
cases, polyps in $18.8 \%$ cases and fibroids in $11.3 \%$ cases [12].

Of $20 \%$ of patients had typical endometrium with Office hysteroscopy in our study, 31 patients had ordinary endometrium with histopatholgy while 10 patients with intrauterine polyps, 8 patients with SM myoma. 6 patients with endometrial hyperplasia analyzed by histopathology. Office hysteroscopy had affectability of $88 \%$, particularity of $84,2 \%$, positive prescient estimation of $96 \%$, negative prescient estimation of $61.5 \%$ and demonstrative precision of $87 \%$ for diagnosing the intrauterine reason for anomalous uterine dying. These outcomes are being upheld by Hatem arrangement, hysteroscopy had an affectability of $91.9 \%$, particularity of $86.5 \%$, positive prescient estimation of $93.2 \%$, negative prescient estimation of $84.2 \%$ and demonstrative precision of $90.1 \%$ for diagnosing etiology of anomalous uterine dying. [10] and Pop arrangement in which hysteroscopy had an affectability of $100 \%$ in the location of intrauterine pathology, explicitness of $81 \%$, the positive prescient estimation of $92 \%$ and the negative prescient estimation of $100 \%$ [13].

We suggest utilizing office hysteroscopy in patients with anomalous uterine draining and doing Office hysteroscopy guided biobsy to whole advantages of the two systems.

\section{Conclusion}

Office hysteroscopy is a straightforward, essential and okay outpatient strategy which permits a satisfactory investigation of the uterine pit under visual control.

Office hysteroscopy has more demonstrative part in assessing patients with anomalous uterine draining particularly in intrauterine polyps and submucous myoma in patients with age bunch $18-40$ years.

\section{References}

[1] M.Khrouf and K.Terras ,Diagnosis and management of formerly called "dysfunctional uterine bleeding" according to PALMCOEIN FIGO classification and the new guidelines. $\mathrm{J}$ Obstet Gynaecol India, Vol.64 (6), PP.38893, 2014.

[2] M.G.Munro, H.O.Critchley, M.S.Broder, I.S.Fraser, FIGO classification system (PALMCOEIN) for causes of abnormal uterine bleeding in nongravid women of reproductive age. Int J Gynecol Obstet, Vol.113, PP.313,2011 .

[3] H.Valson, C.Kulkarni, S.Mukerjee, The role of diagnostic hysteroscopy in abnormal uterine bleeding and its histopathological correlation following blind dilatation and curettage. Int $\mathbf{J}$ Reprod Contracept Obstet Gynecol, Vol.5(3), PP.609-14,2016.

[4] C.A.Salazar, K.Isaacson, Office operative hysteroscopy - an update. J Minim Invasive Gynecol, Vol.25, PP.199e208, 2018.

[5] K.D.Frick, M.A.Clark, D.M.Steinbach's, P.Langenberg, STOP-DUB Research Group. Financial and quality-of-life burden of dysfunctional uterine bleeding among women agreeing to obtain surgical treatment. Women's Health Issues. 2009, Vol.19(1), PP.70-8,2018.

[6] R.Phalak, R.Rawal and V.D.Mule ,Hysteroscopy as a Diagnostic Aid in Gynecology, International Journal of Interdisciplinary and Multidisciplinary Studies, Vol. 2(10), PP.78-83,2015.

[7] H.van Dongen, C.D.de Kroon, C.E.Jacobi, J.B.Trimbos, Diagnostic hysteroscopy in abnormal uterine bleeding: a systematic review and meta-analysis. BJOG 2017, Vol.114, PP.664-75,2017.

[8] A.Gianninoto,

C.Morana, C.Campione,Diagnostic hysteroscopy in abnormal uterine bleeding. Five years' experience. Minerva Ginecol, Vol.55, PP.5761,2017.

[9] A.Panda, S.V.Parulekar, A.Gupta, Diagnostic hysteroscopy in abnormal uterine bleeding and its histopathological correlation. J Obstet Gynecol India, Vol.175, PP.74-6, 2018.

[10] A.Revel, A.Shushan , Investigation of infertile couple/Hysteroscopy with Endometrial biopsy is the goal standard investigation for AUB. Human Reprod. Hum Reprod. Aug, Vol.17(8), PP.1947-9, 2017.

[11] A.Razzaq and S.Shukar-ud-Din ,Role of diagnostic hysteroscopy in case of abnormal uterine bleeding Pak J Surg, Vol.27(4), PP.30915,2014 .

[12] H.Hatem El-Gamal, M.Magda Abd-El-Salam, M.Reda Ghanem and I. Shaymaa Al-Ani,The Egyptian Journal of Hospital Medicine. 72.7 (July 7, 2018): p4765+.The Egyptian J.,Hospital Medicine (July 2018) , Vol. 72 (7), Pp. 4765 $4771 \quad 4765 \quad$ Received:12/6/2018 Accepted:21/6/2018, 2018.

[13] S.Pop Trajkovic Dinic, A.Ljubic, V.Kopitovic, The role of hysteroscopy in diagnosis and treatment of postmenopausal bleeding. Vojnosanit Pregl, Vol. 70(8), PP.747-50, 2017. 